\title{
Sezgisel Algoritmaları Kullanarak Raf Optimizasyonu Çalışması ve Bir Yazılım Uygulaması
}

\author{
Tijen Över Özçelik*, Gül Gündüz ${ }^{2}$ \\ ${ }^{1}$ Sakarya Üniversitesi, Mühendislik Fakültesi, Endüstri Mühendisliği Bölümü, Sakarya, Türkiye (ORCID: 0000-0002-9614-8119) \\ ${ }^{2}$ Abdullah Gül Üniversitesi, Mühendislik Fakültesi, Endüstri Mühendisliği Bölümü, Kayseri, Türkiye (ORCID: 0000-0001-7463-3458)
}

(İlk Geliş Tarihi 1 Ağustos 2019 ve Kabul Tarihi 31 Ağustos 2019)

(DOI: 10.31590/ejosat.606566)

ATIF/REFERENCE: Özçelik, T. Ö. \& Gündüz, G. (2019). Sezgisel Algoritmaları Kullanarak Raf Optimizasyonu Çalışması ve Bir Yazılım Uygulaması. Avrupa Bilim ve Teknoloji Dergisi, (16), 977-982.

\section{Öz}

Otomobil montajının çok sayıda parçadan oluşması, sürekli değişen tüketici talebinden dolayı ürün çeşitliliğine gidilmesi ve fabrika yerleşkesinin belirli bir limitinin olması sebebiyle; raf alanı bir otomotiv fabrikasının neredeyse en sınırlı kaynaklarından birini oluşturmaktadır. Raf alanının etkin, verimli ve doğru yönetimi, hem maliyet açısından performansın en iyilenmesi, hem çalışanların yürüme mesafelerinin azaltılmasıyla hareket mudalarının önlenmesi, hem de artan üretim talebiyle ürün miktarına rağmen fabrika yerleşkesinin aynı kalması açısından kritik önem teşkil etmektedir. Bu çalışmada; kutu çeşidi çerçevesinde, standart raflar kullanılmış ve ergonomik standartları da göz önünde bulundurarak raf optimizasyonu ve raf alanı optimizasyonu gerçekleştirilmiştir. Uygulama bir gerçek hayat problemi olduğu için matematiksel olarak modellenmesi ve optimum çözümlerin bulunması oldukça zordur. Modellenmesi zor olan problemelerin, en uygun değere yakın bir çözüm verebilmesi için sezgisel yöntemlerden faydalanılmıştır. Çalışmada kullanılan ilk metot sezgisel metotlardan biri olan Greedy Algoritmasıdır. Kutular raflara bu algoritmaya göre yerleştirilmiştir. Açgözlü algoritmalar her zaman ve her problem için optimal çözümü vermese de bazı problemler için en uygun çözümü vermektedirler. Bir kerede tek bir karar verme, karar verirken yerel bilgiyi kullanma, karar verirken o an için en çok faydayı bulma gibi işlemler açgözlü probleminin özelliklerindendir. Algoritma en çok faydayı aramaya odaklandığı için açgözlü olarak ifade edilmektedir. Çalışmada kullanılan diğer bir yöntem ise planogram'dır. Raf ve ürün düzenleme yazılımı olan planogram probleme uyarlanmıştır. Planogram; ürünlerin raflarda hangi şekilde düzenleneceğine ve yerleştirileceğine gösteren diyagramları ifade eden yazılımlardır. Ürünlerin raflardan çıkış sırası, boyutları, optimizasyon kuralları ve ergonomi kriterleri göz önüne alınarak oluşturulan yazılım ile belirlenen kısıtlar doğrultusunda en iyiye yakın raf yerleştirme gerçekleştirilmiştir.

\section{Shelf Optimization Study By Using Heuristic Algorithms and A Software Application}

\begin{abstract}
Automobile assembly consists of a large number of parts, due to the ever-changing consumer demand due to the variety of products and factory site has a certain limit; shelf space is almost one of the most limited resources of an automotive factory. Efficient, productivity and accurate management of the shelf area is critical for optimizing the performance in terms of cost, preventing movement breaks by decreasing the walking distance of the employees, and keeping the factory campus the same despite the increasing production demand. In this study; In the box type, standard shelves were used and rack optimization and shelf space optimization were carried out considering ergonomic standards. Since the application is a real-life problem, it is very difficult to model mathematically and to find the optimum solutions. Heuristic methods have been used in order to provide a solution close to the most appropriate value of the problems that are
\end{abstract}

* Corresponding Author: Sakarya Üniversitesi, Mühendislik Fakültesi, Endüstri Mühendisliği Bölümü, Sakarya, Türkiye, ORCID: 0000-0002-96148119 , tover@sakarya.edu.tr 
difficult to model. The first method used in the study is the Greedy Algorithm, which is one of the heuristic methods. Boxes are placed on shelves according to this algorithm. Although Greedy Algorithms do not always provide the optimal solution for every problem, they provide the most suitable solution for some problems. Making one decision at a time, using local information in the decisionmaking process, such as finding the most useful for the decision-making process is a feature of the Greedy problem. The algorithm is expressed as Greedy because it focuses on seeking the most benefit. Another method used in the study is the Planogram. The shelf and product layout software, Planogram, is adapted to the problem. Planogram; software that expresses diagrams showing how products are arranged and placed on shelves. The best possible shelf placement was carried out in line with the constraints determined by the software created by taking into consideration the order, dimensions, optimization rules and ergonomics criteria of the products.

\section{Keywords: Greedy Algorithm, Knapsack Problem, Shelf Optimization, Planogram.}

\section{Giriş}

Raf Optimizasyonu, raflarında ürün tutan bütün firmaların karşına çıkabilecek güncel ve dinamik bir problemdir. Raf optimizasyonu için bu çalışmada olduğu gibi sezgisel yöntemlerden faydalanılabildiği gibi sezgisel olmayan yöntemler de kullanılabilir. Sezgisel olmayan yöntemlerin kullanılması durumunda yani problemin matematiksel olarak modellenebilmesi durumunda ise uygun kısıtlar ve amaç fonksiyonu oluşturularak model çözümlenebilir. Raf optimizasyonu ve raf boşluklarına ürün atanması ile ilgili literatürde çeşitli çalışmalar bulunmaktadır. Bu çalışmalarda belirli bir ürünün sergileme alanı değişiminin tamamlayıcı veya ürünlerin talebi üzerine etkisini ölçen çapraz esneklik raf alanı yönetim modellerinde sıklıkla kullanılmaktadır. "Süpermarketlerdeki raf alanı ve birim satış ilişkisi” konulu makalede; raf değişikliklerinin birim satışlar üzerindeki etkisinin incelenmesinde, alan elastikiyeti fiziksel özellikler, satış özellikleri ve kullanım özellikleri de dâhil olmak üzere ürüne özgü değişkenlerin bir fonksiyonu olarak hipnotize edilmiştir (Churhan, 1972). Model kademeli çoklu regresyon kullanılarak test edilmiştir ve raf alanının birim satışlar üzerindeki etkisinin diğer değişkenlerin etkisine göre çok küçük olduğu tespit edilmiştir. “Optimal Marka Koleksiyonunu ve Sergileme Alanı Tahsisini Eşzamanlı Olarak Belirlemeye Yönelik Matematiksel Bir Model” konulu makale perakende dağıtımına ilişkin temel bir kısa vadeli kaynak tahsisi sorununu ele almaktadır: Aynı anda birçok kişiden gösterilmesi gereken belirli markaları ve bu markalara atanması gereken perakende ürün teşhir alanını bulma problemini, perakende kurumu kârını maksimize ederek sağlamayı amaçlamıştır (Anderson, 1974). "Süpermarkette ürün seçimi ve alan tahsisi” ; bir süpermarkette satılacak ürün çeşitlerinin belirli bir ürün kümesi ve bu ürünlere raf alanı tahsisi arasında eşzamanlı optimal seçim için bir model ve bir algoritma önerilmiştir (Hansen, 1979). Model, satışların alan esnekliğini ve ayrıca seçilen herhangi bir ürünün minimum bir raf alanı alması ve her bir ürüne tahsis edilen raf alanının, tam sayıdaki yüzeye eşit olması gerektiğini sınırlamaları dikkate almaktadır. "Perakende Teşhir Alanı Analizi: Kuram ve Yöntem" konulu makale (Anderson, 1979); Perakende yönetiminin en önemli kısa vadeli kararlarından biri, bir ürün markaları portföyü oluşturmak ve her birine atanması gereken sergileme alanını belirlemektir. Bu makale, tüketici marka tercihlerinin bir profili göz önüne alındığında, marka pazar payları ve ürün teşhir alanı payı arasındaki ilişkinin teorik bir modelini geliştirmektedir. Teori tarafindan önerilen deneye dayalı bir pazar payı esnekliği ölçüsü deneysel veriler kullanılarak istatistiksel olarak değerlendirilmektedir. "Perakende alan tahsislerini optimize etmek için bir model" içeriğini ele alan makalede; rekabetçi ürünler arasında az sayıda raf alanı tahsis edilmesi perakendecilikte merkezi bir sorundur. Alan tahsisi, hem ana hem de çapraz uzay esnekliklerinin dikkate alınması gereken talep fonksiyonu ve maliyet fonksiyonu (satın alma, taşıma ve stok dışı maliyetler) aracılığıyla mağazanın karlılığını etkilemektedir (Corstjens, 1981). Her iki etkiyi de benzersiz bir şekilde içeren bir model geliştirilmiştir. Parametreleri tahmin etmek için bir vaka çalışması kullanılmış ve problem geometrik bir programlama çerçevesinde çözülmüştür. Alternatif prosedürlerle yapılan kapsamlı bir karşılaştırma, bu genel modelin önemli ölçüde farklı tahsisat kurallarına ve üstün kâr performansına yol açtığını göstermektedir. Çapraz esnekliği temel alan modeller genellikle "NPZor" yapısı içinde sınıflandırıldığından modeli çözmek amacıyla pek çok çalışmada sezgisel yöntemler önerilmiştir. Benzetimli tavlama, tabu arama algoritması, ağ akış modeli, genetik algoritma, sırt çantası ve açgözlü yaklaşım, esaslı birçok metot raf alanı problemlerinden başarılı sonuçlar elde edilmesini sağlamıştır (Bai ve arkadaşları, 2008; Borin ve arkadaşları, 1994; Lim ve arkadaşları, 2002\&2004, Hwang ve arkadaşları, 2009; Urban; 2005; Özcan \& Esnaf, 2010). "Entegre bir raf alanı tasarımı ve ürün tahsisi problemine genetik algoritma yaklaşımı" ile hazırlanan makale; raf alanında sergileyerek çeşitli markalarda ürün satan perakendecilerin sorunlarını ele almaktadır. Perakendecinin kârını en üst düzeye çıkarmak amacıyla raf alanı tasarımı ve ürün tahsisat sorunu için entegre bir matematik modeli geliştirilmiştir (Hwang ve arkadaşları, 2009). "Raf alanı optimizayonu” konulu çalışma; raf boşluklarının atanması problemini çözmek için uygun ürünleri uygun raflara atayarak kârı en iyileştirmeyi amaçlamaktadır (Academia, 2007). Bu çalışmada ise bir sezgisel yaklaşım olan greedy algoritmasından faydalanılmıştır. Greedy algoritmasının tam optimizasyonu sağlayamadığı durumu gidermek için planogramdan faydalanılmıştır. Literatürde; raf alanı yönetimi kapsamına giren raf boşluklarının atanması ve raf optimizasyonu problemi ile ilgili sezgisel bir yaklaşımla planogramı birlikte kullanan sınırlı sayıda çalışma bulunmaktadır. Bu konudaki literatür çalışmaları işletmede yaşanan problemin çözümüne ilham kaynağı olmuştur.

Çalışmada; raflara kutu atanması ilk etapta Greedy algoritması ile gerçekleştirilmiştir. Bu atama işlemi için, 3 raf tipine 6 farklı kutu tipinin yerleştirilmesi Greedy algoritması ile modellenmiştir. Bu optimizasyon probleminde Greedy algoritması ve sırt çantası problemi mantığı ile değerlere, öneme göre en uygun yerleştirme yapılması hedeflenmiştir. Mevcut raf boşluklarına ürün atanması ve raf optimizasyonun sağlanması probleminde çok çeşitli kısıtlar bulunmaktadır. Ağır parçaların rafın orta katına yerleştirilerek ergonominin sağlanması, her parçanın raf stok maximum sayısı, kutuların derinlik, genişlik ve yükseklik ölçülerinin yanında rafların derinlik, genişlik ve yükseklik ölçülerine göre en fazla kutu yerleştirilmesini sağlamak için ilk etapta kullanılan Greedy algoritması en uygun çözüm için yetersiz kalabilmektedir. Amaç raflara; ergonomik kriterlere, kutu stok maximum sayısı kısıtına uygun biçimde en fazla kutuyu yerleştirerek optimizasyonu sağlamak ve firmaya bu sonuçları gösteren bir raf haritası vermektir. Bir ürünün veya ürün grubunun satış rakamlarının analizini yaparak, raflarda nasıl sergileneceğini gösteren çizimler olan planogramlar, kutuların parça listesi kullanım sırası, ergonomi kriterleri ve açgözlü mantığ 1 göz önüne alınarak oluşturulmuştur. Yazılım sonucu belirlenen kısıtlar doğrultusunda parçalar raflara yerleştirilerek en iyiye yakın planogram görüntüleri elde edilmeye çalışılmıştır. Bu planogram için yazılım yapılırken; Microsoft 
access programına aktarılan parça listesiyle entegre çalışacak bir program yazılıış, bu program yazılırken Visual Studio C\#'dan faydalanılmıştır. Mevcut raf planı program çalışıktan sonra optimizasyon yapılmış sonucu Excel'e aktararak çıktı alınabilmektedir.

Çalışmanın organizasyonu; birinci bölümünde raf optimizasyonu genel giriş ve ilgili literatür araştırması, ikinci bölümde kullanılan metotlar, üçüncü bölümde uygulama çalışması için hazırlanan yazılım ile Greedy algoritmasının karşılaştırılması ve son bölümde ise raf haritası yazılımının sonuçlarının geliştirilmesi için önerilerden oluşmaktadır.

\section{Materyal ve Metot}

\subsection{Sezgisel Optimizasyon Algoritmaları}

Yöneylem araştırması teknikleri ve modelleme mantı̆̆ belirli bir probleme yönelik en uygun çözümün bulunmasını amaçlayan yöntemler bütünü olarak ifade edilmektedir. Dünya üzerindeki gerçek karmaşık problemlere matematiksel modelleme, algoritma ve istatistik gibi bilimsel yöntemlerden faydalanarak çözümler sunan bir bilim dalıdır. En uygun çözümün bulunmasını isteyen problemler ise optimizasyon problemleri olarak sınıflandırılabilir (Berberler, 2009). Tavlama benzetimi, Genetik algoritmalar, karınca kolonisi, parçacık sürü optimizasyonu, çok yönlü ve hibrit metotları, evrimsel algoritmalarda kısıt ele alma teknikleri, yapay arı kolonisi, greedy algoritması bazı sezgisel algoritmalardan birkaçıdır. Sezgisel optimizasyon algoritmaları en mükemmel çözümü bulmayı garanti etmeyen, algoritmanın ne kadar kısa sürede, ne derece iyi çözüme ulaşıyorsa o kadar etkili kabul edileceği mantığı ile çalışan yaklaşımlardır.

\subsubsection{Sırt Çantası Problemi ve Greedy (Açgözlü) Algoritması}

Sırt çantası problemleri tamsayılı programlama problemlerinin bir alt türüdür. Bu problemlerin içinde en basit olan tür olarak kabul edilmesinin nedeni, problemin tanımlanmasının anlaşılabilir olması ve gerçek hayatta yüzleşilebilecek pek çok durumun bu probleme göre kolay bir biçimde ifade edilebilmesidir. Günümüzde sırt çantası problemi, bilim adamları tarafından yoğun bir şekilde çalışılmakta ve araştırılmaktadır. Bu popülerliğin sebebi ise, problemin kolay olması ve birçok endüstriyel alana uygulanabilmesidir. Sermaye bütçeleme, proje seçimi, kargo yükleme, kesme gibi problemler sırt çantası şeklinde modellenebilen problemlerden birkaçı1ır. Problem s tek bir kısıt ve sadece pozitif katsayılarla ifade edilen en basit tamsayılı model olarak bilinmektedir. Fakat değişkenlerin tamsayı olma koşulu sırt çantası problemini NP-tam sınıfı içine yerleştirmektedir. Sırt çantası problemi, bir maksimizasyon problemidir, kesikli optimizasyon problemleri içerisinde tam sayılı doğrusal programlamanın en basit olan çeşididir (Berberler, 2009).

Sezgisel bir yöntem olan açgözlü türündeki algoritmalar tasarım kolaylığı ve optimum çözüme yaklaşımı açısından oldukça kullanışlı bir yöntemdir. Bir seferde tek bir karar verir, karar verirken yerel bilgiyi kullanma, karar verirken o an için en fazla faydayı gözetme açgözlü algoritmasının özelliklerindendir. Başka bir ifadeyle en uygun çözüme götürebilir yaklaşımıyla yerel en uygun seçimler yapmaktadır. Açgözlü algoritması başlangıç olarak nesneleri bazı kıstaslara göre sıralar ve boş kümeden başlayamak üzere çözüm kümesini genişletmeye çalışır. Yani yukarıda verilen ilk özellik kullanılır: Tek seferde tek nesne için karar verilmektedir. Sondaki çözümün uygun olması durumunda, nesne o anki geçerli çözüme eklenirken; aksi durumda bir daha işleme girmemek üzere elenmektedir (Berberler, 2009).

\subsection{Planogram}

Planogram; ürünlerin mağaza raflarında veya depo raflarında ideal durumdaki sergilenmelerini tasarlamak için kullanılan ve bilgisayarda çeşitli yazılımlar vasıtasıyla hazırlanan bir yerleşim planı diyagramıdır. Piyasada her raf tipine uygun ihtiyaçlara göre hazırlanmış özel planogram programları bulunmaktadır. Ayrıca, planogram elle, paintte, photoshopta veya herhangi bir uygun programda da çizilebilmektedir (Arslan, 2014). Planogramlar, her bir ürünün fiziksel olarak tam olarak hangi rafa, rafın kaçıcı katına ve ürünün hangi yüzünün mağaza raflarına ya da depo raflarına yerleştirilmesi gerektiğini göstermek için kullanılmaktadır. Sınırlı raf alanı kapasitesi problemi sebebiyle, planogramlar maddi getiriyi optimize etmek amacıyla kullanılan önemli yerleşim uygulamalarındandır. Elektronik planogramlar ise stok kontrolü ve satıcı ilişkisinin iyileştirilmesi için de kullanılabilen önemli araçlardandır. Fakat planogram üretmek ve tasarlamak zor ve zaman alıcı bir süreci oluşturmaktadır. Çünkü planogram probleminin en basit şekli, hali hazırda çözülmesi çok zor olarak bilinen bir "NP-zor problemi" olan birçoklu sırt çantası problemi olarak tanımlanmaktadır (Bai\&Kendal, 2005).

\section{Uygulama}

Belirlenen raf standartları doğrultusunda $110(7 \mathrm{~kat}) \mathrm{cm}$ 'lik raflar, 220(5 kat) cm'lik raflar ve 330(4 kat) cm'lik raflar bulunmaktadır. Parça listesindeki kutu ölçülerine ve minimum ve maximum parça listesine göre raflara kutu ataması yapılması istenmektedir. Her kutu tipine ve rafına göre kutuların kaç çok kat besleneceği, ergonomi kurallarına göre ve en uygun şekilde nasıl besleneceği üzerine bir uygulama çalışması hazırlanmıştır. 


\begin{tabular}{|c|c|c|c|}
\cline { 2 - 4 } \multicolumn{1}{c|}{$\begin{array}{c}\text { Kutu } \\
\text { Sayısı }\end{array}$} & \multicolumn{2}{c|}{ Kat sayısı } & Kutu sayısı \\
\hline Ürün no & \multicolumn{2}{|c|}{$2 \mathrm{~kat}$} & \multicolumn{2}{c|}{$10 \mathrm{adet}$} \\
\hline $\mathbf{x x x x}$ & $550 \mathrm{~cm}$ & $\begin{array}{c}355 \\
\mathrm{~cm}\end{array}$ & $165 \mathrm{~cm}$ \\
\hline
\end{tabular}

Şekil 1. Yerleşim Yapılacak Bir Kutunun Bilgi İçerikleri

Şekil 1' de örnek bir kutu yerleşim bilgisi verilmiştir. Kutu sayısı içine kaç adet kutu yerleştirileceği, kat sayısına aynı kutudan üst üste kaç kat yerleştirileceği, ürün numarası bilgisi ve kutunun uzunluk genişlik ve yükseklik ölçüleri gibi bilgileri gösterilmiştir. Raflara kutu atamaları, her kutunun ve her rafın bilgi içeriğine göre gerçekleşmektedir. Örneğin $330 \mathrm{~cm}$ 'lik bir raf için 165 cm'lik kutudan 2 kat beslenebilmektedir. $165 \mathrm{~cm}$ yüksekliğindeki kutu $110 \mathrm{~cm}$ yüksekliğindeki rafa yerleştirilemez fakat $220 \mathrm{~cm}$ 'lik rafa tek kat besleme şeklinde atama yapılabilmektedir. X,Y ve Z üç farklı raf çeşidini ifade eden semboller olurken, SN, FB ve FC ise farklı ölçülere sahip kutuların çeşitlerini temsil etmektedir. SN kutusu $355 \mathrm{~cm}$ uzunluğa, $280 \mathrm{~cm}$ genişliğe ve $40 \mathrm{~cm}$ derinliğe sahip bir kutu için kullanılan temsili ifadedir. FB kutusu $355 \mathrm{~cm}$ uzunluğu, $275 \mathrm{~cm}$ genişliği ve $245 \mathrm{~cm}$ derinliği olan bir kutu için kullanılırken, FC kutusu $355 \mathrm{~cm}$ uzunluğu, $550 \mathrm{~cm}$ genişliği ve $165 \mathrm{~cm}$ derinliği olan bir kutu çeşidini temsil etmektedir.

Tablo 1. Kutu tiplerinin raf tiplerine göre fayda getirileri, kâr ilişkileri ve bulunması gereken kutu sayıları

\begin{tabular}{|l|l|l|l|l|l|l|}
\hline \multirow{2}{*}{} & \multicolumn{6}{|l|}{ Kutularin uzunluklari ve raflardaki getirileri } \\
\cline { 2 - 7 } & Raf $\boldsymbol{X}$ & $\operatorname{Raf} \boldsymbol{Y}$ & $\operatorname{Raf} \boldsymbol{Z}$ & Kutu $\boldsymbol{L}$ & Kutu $\boldsymbol{W}$ & Kutu $\boldsymbol{H}$ \\
\hline SN & 1,50 & 0.5 & 0.25 & 355 & 280 & 40 \\
\hline $\boldsymbol{F B}$ & 0 & 0 & 2 & 355 & 275 & 245 \\
\hline $\boldsymbol{F C}$ & 0 & 1 & 3 & 355 & 550 & 165 \\
\hline $\begin{array}{l}\text { Raf } \\
\text { uzunluğu }\end{array}$ & 110 & 220 & 330 & & & \\
\hline
\end{tabular}

\begin{tabular}{|c|c|c|c|c|c|c|}
\hline \multicolumn{4}{|c|}{ Kutuların birbirleriyle olan kâr ilişkisi } & \multirow{2}{*}{\multicolumn{3}{|c|}{$\begin{array}{c}\text { Raflarda bulunması gereken } \\
\text { min-max kutu sayısı }\end{array}$}} \\
\hline \multirow[b]{2}{*}{ SN } & \multirow{2}{*}{$\begin{array}{l}\text { SN } \\
1\end{array}$} & \multirow{2}{*}{$\begin{array}{l}\text { FV } \\
0 \\
\end{array}$} & \multirow{2}{*}{$\begin{array}{l}\text { FC } \\
0\end{array}$} & & & \\
\hline & & & & & Min & Max \\
\hline FB & 0 & 1 & 0.5 & SN & 20 & 160 \\
\hline FC & 0 & 0.5 & 1 & $\overline{\text { FB }}$ & 12 & 1030 \\
\hline & & & & FC & 14 & 105 \\
\hline
\end{tabular}

Tablo 1' de 3 farklı kutu tipi ve 3 farklı raf tipinin genişlik, uzunluk ve yükseklik bilgilerinin yanında raf-kutu fayda getiri bilgileri de tabloda verilmiştir. Kutuların birbiriyle olan kâr ilişkileri ve raflarda bulunması gerekn kutu türüne göre değişen maksimum ve minimum kutu sayısı miktarları tablo içeriğinde sergilenmiştir.

Tablo 2. SN kutuların greedy yaklaşımına göre yerleştirilmesi

\begin{tabular}{|c|c|c|c|c|c|c|c|c|}
\hline \multirow{7}{*}{ RAF-X } & $S N * 2$ & $S N * 2$ & $S N^{* 2}$ & $S N^{*} 2$ & $S N * 2$ & $S N * 2$ & $S N * 2$ & 7.kat \\
\hline & $S N^{*} 2$ & $S N^{*} 2$ & $S N^{* 2}$ & $S N^{*} 2$ & $S N * 2$ & $S N^{* 2}$ & $S N^{*} 2$ & 6. kat \\
\hline & $S N^{*} 2$ & $S N^{* 2}$ & $S N * 2$ & $S N^{*} 2$ & $S N * 2$ & $S N^{*} 2$ & $S N * 2$ & 5.kat \\
\hline & $S N^{*} 2$ & $S N^{* 2}$ & $S N * 2$ & $S N^{*} 2$ & $S N * 2$ & $S N^{* 2}$ & $S N * 2$ & 4.kat \\
\hline & $S N^{* 2}$ & $S N * 2$ & $S N^{* 2}$ & $S N^{*} 2$ & $S N * 2$ & $S N^{* 2}$ & $S N^{* 2}$ & 3. kat \\
\hline & $S N^{*} 2$ & $S N^{* 2}$ & $S N^{* 2}$ & $S N^{* 2}$ & $S N * 2$ & $S N^{*} 2$ & $S N * 2$ & 2.kat \\
\hline & $S N^{*} 2$ & $S N * 2$ & $S N^{*} 2$ & $S N^{*} 2$ & $S N * 2$ & $S N^{*} 2$ & $S N^{* 2}$ & 1. kat \\
\hline
\end{tabular}

Öncelikli olarak raf X' e yerleştirme yapılmalıdır. Tablo 1 incelendiğinde, getirisi en yüksek olan SN kutu tipi seçilmesi gerektiği görülmektedir. Tablo 1'de kutuların birbiriyle ilişkisi incelendiğinde ise görüldüğü gibi karı en yüksek SN kutu yanına SN kutu gelmesi durumu uygundur. Raf X ölçüsünü SN kutu ölçülerine bölerek rafın kaç kutu alabildiği hesaplanmaktadır. Örnekteki gibi; $2500 \mathrm{~cm}$ raf uzunluğunu $355 \mathrm{~cm}$ olan kutu uzunluğuna bölüp çıkan sonuç olan 7’yi, $1980 \mathrm{~cm}$ olan raf genişliğini $280 \mathrm{~cm}$ olan kutu genişliğine bölüp çıkan sonuç olan 7'yi ve $110 \mathrm{~cm}$ olan raf yüksekliğini $40 \mathrm{~cm}$ olan kutu yüksekliğine bölüp çıkan sonuç olan 2'yi çarparak elde edilen 98 adet kutu bulunması ve 7 katlı rafa, 2 katlı kutular şeklinde beslenmesi tablo 2'de gösterilmiştir. Buna göre elde edilen kâr, çapraz kâr durumlarını da göz önüne alındığında; RAF-X=(SN Kutusunun X nolu raftaki kârı)*(X nolu raftaki SN kutu âdeti)*Raf katı sayıs1 
RAF-X=1.5*98*7=1029 değeri bulunmuştur. Bu rafa yerleştirmede kullanılan algoritma açgözlü ve sirt çantası problemi mantı̆̆ göz önüne alınarak hazırlanmıştır. Ağır kutular için rafların orta katları tercih edilmiştir, çalışanın ergonomik açıdan rahatlığı göz önünde bulundurulmuş̧ur.

\subsection{Uygulamanın Optimizasyonu İçin Hazırlanan Planogram Yazılımı}

Planogramın stok raflarındaki verimliliğinden faydalanmak için sezgisel mantıkla çalışan bir yazılım geliştirilmiştir. İlk adım olarak parça listesini Access haline getirdikten sonra C\#' da gerekli kodlar yazılarak bu accesten raf haritası için uygun kolonların çekilmesi sağlanmıştır. Gerekli sütunlar; kutu numarası, tipi, derinliği, genişliği, yüksekliği ve maximum sayısıdır. Program raf derinlik, genişlik ve yüksekliğini; kutu derinlik, genişlik ve yüksekliğine bölüp maxstore sayılarına bakarak en çok kutu kapasitesi sağlamayı hedeflemektedir. Bu işlemi yaparken ağır kutuları da ergonomik olarak yerleştirmektedir. Kutu ağırlıklarına bakarak ağır kutuyu en alt rafa ve en üst rafa yerleştirmeyi engelleyerek alımı kolay raf katlarına yerleşimi sağlamaya yönelik algoritmalar yazılmıştır. Sonraki adımda çekilen bilginin programa işlenmesini sağlamak için getir butonuna basarak gerekli parça bilgisine erişilmektedir. En son adım ise oluşturulan raf haritası optimizasyonunun excele aktarılmasıdır.

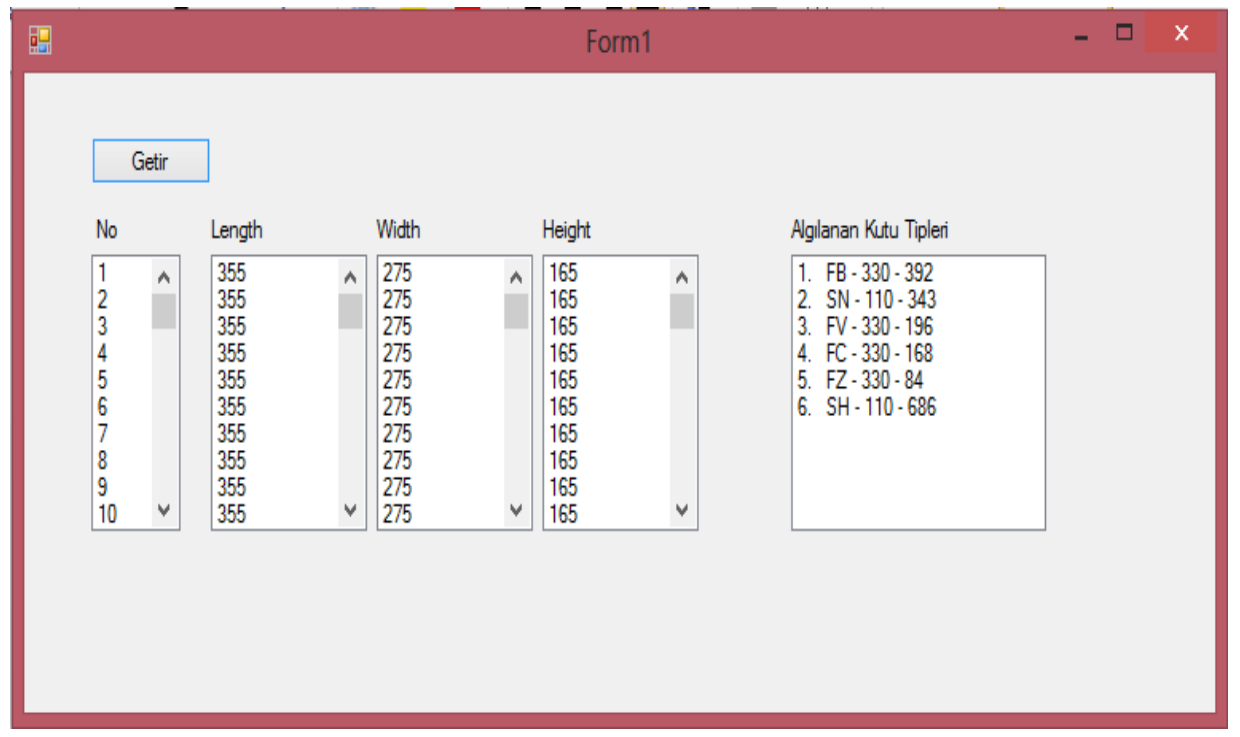

\begin{tabular}{|c|l|l|l|r|}
\hline $\begin{array}{c}\text { Raf } \\
\text { No }\end{array}$ & $\begin{array}{c}\text { Ürün } \\
\text { No }\end{array}$ & Max & $\begin{array}{c}\text { Raf } \\
\text { Tipi }\end{array}$ & $\begin{array}{c}\text { Kutu } \\
\text { Tipi }\end{array}$ \\
\hline$A 8$ & 3349 & 2 & 110 & $S N$ \\
\hline$A 8$ & 3469 & 6 & 110 & $S N$ \\
\hline$A 8$ & 9692 & 16 & 110 & $S N$ \\
\hline$A 8$ & 9723 & 7 & 110 & $S N$ \\
\hline$A 8$ & 3619 & 2 & 110 & $S N$ \\
\hline$A 8$ & 3712 & 10 & 110 & $S N$ \\
\hline$A 8$ & 4386 & 13 & 110 & $S N$ \\
\hline$A 8$ & 4432 & 9 & 110 & $S N$ \\
\hline$A 1$ & 1009 & 2 & 330 & $F B$ \\
\hline$A 1$ & 1062 & 2 & 330 & $F B$ \\
\hline$A 1$ & 1238 & 2 & 330 & $F B$ \\
\hline$A 1$ & 1372 & 2 & 330 & $F B$ \\
\hline$A 1$ & 1435 & 2 & 330 & $F B$ \\
\hline$A 1$ & 1497 & 2 & 330 & $F B$ \\
\hline$A 1$ & 1541 & 2 & 330 & $F B$ \\
\hline$A 1$ & 1625 & 2 & 330 & $F B$ \\
\hline$A 1$ & 1708 & 2 & 330 & $F B$ \\
\hline
\end{tabular}

Şekil 2.Getir Butonuna Basılarak Veri Aktarmave Optimize Edilen Rafin Excel Formatı

Şekil 2'de program arayüzü ve veri aktarma formu gösterilmiştir. Ergonomi kurallarına ve açgözlü algoritmasına göre optimize edilen rafin yerleşim düzeninin bir excel formuna aktarılması bu buton arka planındaki yazılım sayesinde elde edilmektedir.

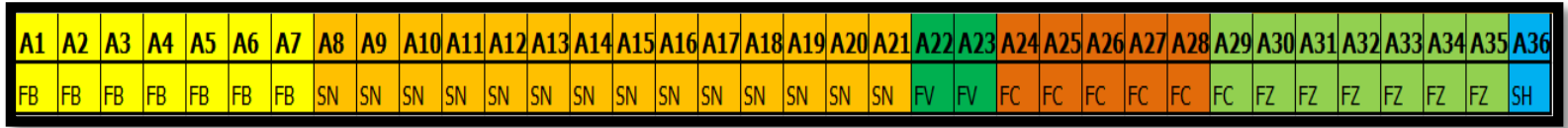

\section{Şekil 3. RafOoptimizayonu Yapılmış Haritanın Yukarıdan Görünüşü}

Şekil 3’te ise program ile atanan kutuların raf düzenine aktarılması ve haritanın yukarıdan görünüşü verilmiştir. Raf optimizasyonuna göre hazırlanan 36 raflı düzende, her raf tipinde bulunması gereken kutu tipi ataması yapılmıştır.

\section{Sonuç}

Bu çalışmada; raf boşluklarının atanması ve raf optimizasyonu için bir sezgisel yaklaşım olan greedy algoritması geliştirilmiştir. Geliştirilen modelin; etkinliği bir otomobil firmasından alınan verilerle gerçekleştirilen küçük ölçekli bir örnek ile sunulmuştur. Modelin Karmaşık yapısından dolayı, model çözümü için Visual studio C\# altında çalışan planogrom tabanlı bir raf haritası yazılımından faydalanılmıştır. Bu çalışmanın katkıları literatür açısından ve firmalar açısından oldukça fazladır. Literatürdeki çalışmalarda sadece sezgisel algoritma ya da sadece tamsayılı programlama yöntemleri kullanarak geliştirilen modeller bir planogram yazılımı sayesinde simüle edilme firsatı bulunmuştur. Geliştirilen yaklaşım büyük ölçekli raf alanı yönetim problemlerine de uygulanabilecek esnekliktedir. Kutu sayısı ve raf tipi gibi değişiklikler esnek yazılım sayesinde kolaylıkla değiştirilebilecek ve optimizasyon sağlanmış olacaktır. Ancak; bu problemlerin çözümü için farklı sezgisel yaklaşımlara ve daha güçlü bilgi teknolojisi araçlarına ihtiyaç duyulacaktır. Raf haritası yazılımı talep edilen firmada manuel olarak excelde yapılırken ve yaklaşık olarak 1 ay süre almaktayken aynı zamanda 2 işgücü 
bu konuda çalışmaktaydı. Manuel olarak yapılan işlemde unutulan kutular ve yanlış girilen sayılar yazılan program sayesinde minimize edildi. Yapılan çalışma sayesinde 2 işgücü 1 işgücüne indirildi. A42 olarak gösterilen 42 adet raftan 36 tanesi kullanılarak 6 adet raf ve raf alanından kazanıldı. Raf haritası çalışması soft ortama aktarılarak 1 aylık süreden 45 sn'lik bir süreye indirilirken bu işten kazanılan zaman ve işgücü ile firma başka sorunlarını çözmeye odaklanacak firsatlar buldu. Bu çalışma rafta stok tutan başka firmalar içinde revize edilip kullanılabilme niteliği taşımaktadır. Program herhangi bir veri değişikliği için gerekli esnekliklere sahiptir.

\section{Kaynakça}

Ronald C. Curhan, (1972). The Relationship Between Shelf Space and Unit Sales in Supermarkets, Journal of Marketing Research, Cilt: 9; No: 1; sf.: 406-412.

E. Evan Anderson, Henry N. Amato, (1974). A Mathematical Model for Simultaneously Determine The Optimal Brand-Collection and

Display-Area Allocation, Operations Research, Cilt: 22, No: 1; sf.: 394-406.

Pierre Hansen, Hans Heinsbroek, (1979) .Product Selection and Space Allocation in Supermarket, European Journal of Operational Research; Cilt: 3; No:6; sf.: 474 4484

E. Evan Anderson; (1979). An Analysis of Retail Display Space: Theory and Methods, Journal of Business, Cilt: 52, No: 1; sf.: $103 \neg 118$.

Marcel Corstjens, Peter Doyle, (1981). A Model For Optimizing Retail Space Allocations, Management Science, Cilt: 27; No:7; sf.: $822 \neg 833$.

Yunus Demir, Cafer Çelik, (2016). Müfredat Bazlı Akademik Zaman Çizelgeleme Probleminin Çözümüne Tam Sayılı Doğrusal Programlama Yaklaşımı, Gazi Üniversitesi Mühendislik Fakültesi Dergisi, Cilt 31, Sayı 1.

Ruibin Bai, Edmund K. Burke, Graham Kendall, (2008). Heuristic, Meta-heuristic and Hyper-Heuristic Approaches for Fresh Produce Inventory Control and Shelf Space Allocation, Journal of the Operational Research Society, doi:10.1057, sf.: 1-11.

Norm Borin, Paul W. Farris, James R. Freeland, (1994). A Model for Determining Retail Product Category Assortment and Shelf Space Allocation, Decision Science, Cilt: 25; No: 3; sf.: 359-384.

Andrew Lim, Brian Rodrigues, Xingwen Zhang, (2004). Metaheuristics with Local Search Techniques for Retail Shelf-Space Optimization, Management Science, Cilt: 50; No: 1; sf::117-131.

Andrew Lim, Brian Rodrigues, Fei Xiao, Xingwen Zhang, (2002) Adjusted Network Flow for the Shelf-Space Allocation Problem, Proceedings of the 14th IEEE International Conference on Tools with Artificial Intelligence; sf.: 224230.

Hark Hwang, Bum Choi, Grimi Lee, (2009). A Genetic Algorithm Approach to An Integrated Problem of Shelf Space Design and Item Allocation, Computers and Industrial Engineering, Cilt: 56; No: 3; sf.: 809-820.

Timothy L. Urban, (2005). An Inventory Theoretic Approach to Product Assortment and Shelf Space Allocation, Journal of Retailing, Cilt: 74; No:1; sf.: 15-35.

Bilal Saim, Sezgisel Arama Algoritmaları, Erişim Adresi https://www.bilalsaim.com/sezgisel-optimizasyon-algoritmalari-heuristicalgorithms-h1632.

Murat Erşen Berberler, (2009). Surt Çantası Problem Türleri ve Uygulamaları, Ege Üniversitesi, Fen Bilimleri Enstitüsü, Doktora tezi,

Semih Arslan, (2014). Erişim Adresi https://markamuduru.com/planogram-nedir/ .

Ruibin Bai, Graham Kendall (2005). An Investigation of Automated Planograms Using a Simulated Annealing Based HyperHeuristic, Operations Research/Computer Science Interfaces Series book series (ORCS, volume 32).

Mustafa Ayhan, YAEM, (2007). Erişim Adresi https://www.academia.edu/2283596/RAF_ALANI_OPT\%C4\%B0M\%C4\%B0ZASYO NU SHELF_SPACE_OPTIMIZATION.

Tuncay Özcan, Şakir Esnaf, (2010). Perakende Endüstrisinde Raf Alanı Tahsis ve Mağaza Yerleşim Optimizasyonuna Bütünleşik Bir Model Önerisi, İstanbul Üniversitesi, Mühendislik Fakültesi Dergisi, 1, 55-63. 